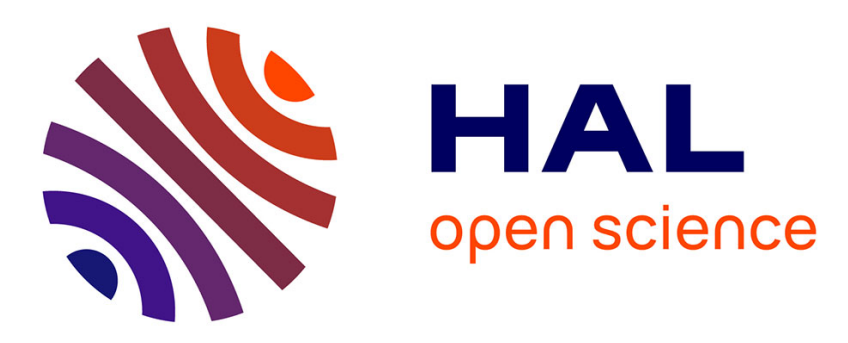

\title{
Potential of Active Ultrasound Monitoring Systems for Jellyfish Detection
}

Gabriel Vasile, Guy d'Urso, Goarant Anne, Eric de Oliveira, Elena Lungu

\section{To cite this version:}

Gabriel Vasile, Guy d'Urso, Goarant Anne, Eric de Oliveira, Elena Lungu. Potential of Active Ultrasound Monitoring Systems for Jellyfish Detection. OCEANS 2016 - OCEANS '16 MTS/IEEE. The Sea's the Limit, Sep 2016, Monterey, CA, United States. pp.4. hal-01387473

\section{HAL Id: hal-01387473 \\ https://hal.science/hal-01387473}

Submitted on 25 Oct 2016

HAL is a multi-disciplinary open access archive for the deposit and dissemination of scientific research documents, whether they are published or not. The documents may come from teaching and research institutions in France or abroad, or from public or private research centers.
L'archive ouverte pluridisciplinaire HAL, est destinée au dépôt et à la diffusion de documents scientifiques de niveau recherche, publiés ou non, émanant des établissements d'enseignement et de recherche français ou étrangers, des laboratoires publics ou privés. 


\section{Potential of Active Ultrasound Monitoring Systems for Jellyfish Detection}

\author{
Gabriel Vasile \\ Grenoble-Image-sPeech-Signal-Automatics Lab \\ CNRS / Grenoble-INP, UMR 5216 CNRS \\ Grenoble Cedex, France, F-38402 \\ gabriel.vasile@gipsa-lab.grenoble-inp.fr
}

\author{
Guy d'Urso, \\ Anne Goarant \\ and Eric de Oliveira \\ EDF R\&D, Chatou, France \\ guy.durso@edf.fr
}

\author{
Elena Lungu \\ SIGnal INformatics TEChnology \\ SIGINTEC \\ Nîmes, France, F-30000 \\ elungu@sigintec.fr
}

\begin{abstract}
This paper investigates the potential of active ultrasound jellyfish monitoring systems to continuously detect, quantify and identify different species in turbulent underwater environments. The experimentations carried out in December 2015 at the Aquarium de Paris, France, are used to propose an unified acoustic signal processing framework for visualizing jellyfish passages.
\end{abstract}

\section{INTRODUCTION}

A fast increase in jellyfish population can be one important indicator of the recent climate changes in seawater. This may be due to the effect of anthropic activity, such as over fishing, global warming, pollution, or coastal development [1].

Such clogging organism, like jellyfish, can pose a significant threat to power plant cooling water intake structures in the context of nuclear power production. In sufficient quantities, these organism can block intake screening equipment (for example, bar racks and traveling water screens), which can lead to reduced cooling water flow or, in extreme cases, structural failure of the screening equipment. Furthermore, the passage into the circulating water system can result in plugging of the condenser tubes. Cooling water blockage is a concern because it negatively affects facility reliability and results in a loss of revenue. One can cite the cluster of jellyfish that forced the Oskarshamn plant from Sweden, the site of one of the world's largest nuclear reactors, to shut down in 2013 by clogging the pipes conducting cool water to the turbines.

A way to reduce the impact of the clogging, is to detect the clogging organism to prevent the power plant. Two main methods have been developed and used for monitoring jellyfish: the towing and scooping techniques for samples collection [2]. All these methods require manual and heavy processes (jellyfish manipulation) or they depend on light and water condition.

In this context, an active ultrasound monitoring system has the potential to efficiently contribute to detect, quantify and identify in the water column the jellyfish species continuously. This paper investigates the first results obtained using the active ultrasound jellyfish monitoring system experimented in December 2015 at the Aquarium de Paris, France. The two types of jellyfish that were inspected are illustrated in Fig. 1.

The remainder of the paper is structured as follows. Section II shows the details of the experiment carried out in controlled environment, as well as the setup of the proposed active

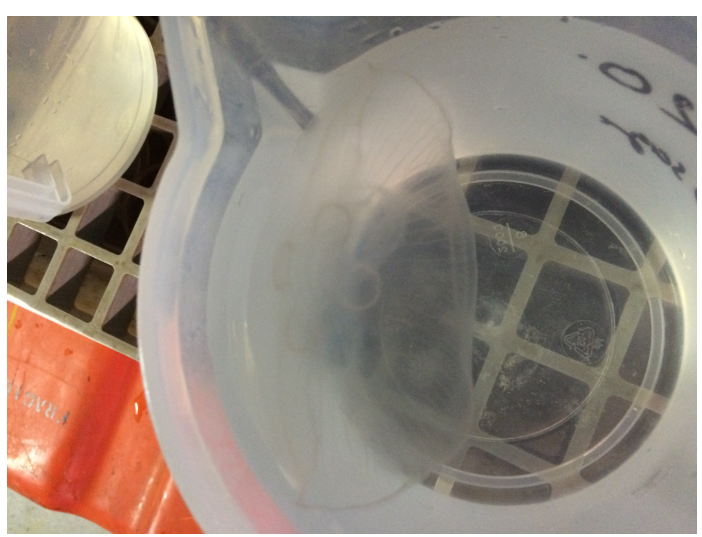

(a)

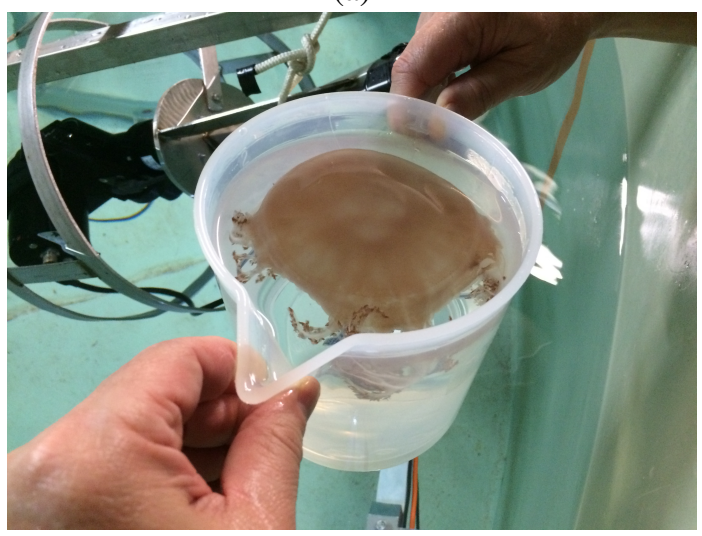

(b)

Fig. 1. Jellyfish used in the experiment at the Aquarium de Paris: (a) species 1 and (b) species 2 .

ultrasound monitoring system. In Section III, we illustrate the obtained results, whereas Section IV concludes the paper.

\section{Active Ultrasound Monitoring System}

The current prototype system was developed in collaboration between the GIPSA-lab, the EDF R\&D and the SIGINTEC, and it is composed of a multi-static acoustic wall operating at $1 \mathrm{MHz}$ central frequency. As illustrated in Fig. 2 , it is composed of several transmitters (Ultran Group WS100-1), receivers (Ultran Group KS-100-1) and a reflecting metallic mirror. 


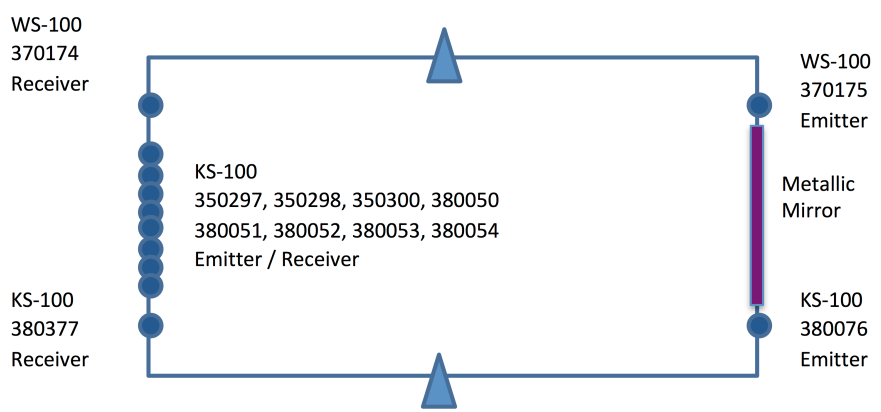

(a)

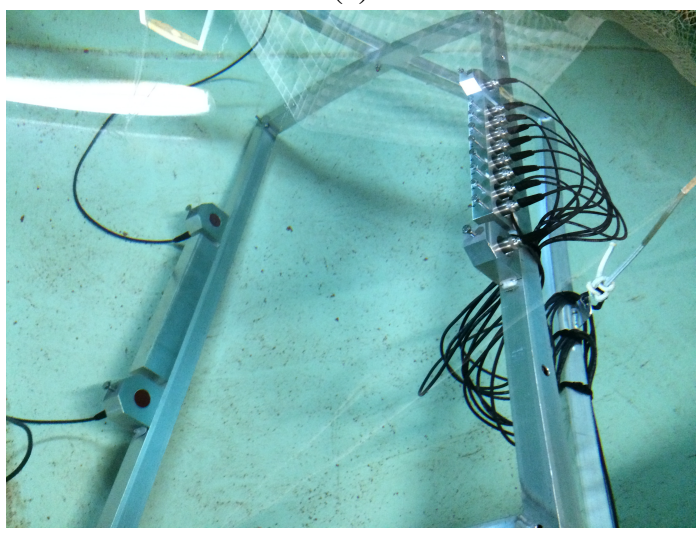

(b)

Fig. 2. (a) setup of the ultrasound transducers on the mobile alluminium frame $(0.8 \times 1.2$ meters $)$ and (b) general view of the experimentation.

The US transducers have been excited using Apex Microtechnology PA107 power amplifiers and the Keysight 33522B arbitrary signal generator. The received signals have been conditioned using Texas Instruments VCA 5807 low noise amplifiers and recorded using four synchronous TiePie HS4 oscilloscopes.

In the first step, the proposed ultrasound monitoring system has been calibrated in order to make the derived measurements independent on the transfer function of the acoustic transducers.

Calibration by substitution requires a reference standard, to which the output is reported. For our system of sensors, the calibration process determines a relationship between the input voltage controlling the EM US transducer and the output characteristic. Illustrated in Fig. 3, the calibration procedure has been realized using a Precision Acoustics ML4X50 hydrophone (operating frequency range $100 \mathrm{kHz}$ to $1 \mathrm{MHz}$ ). Finally, the exact geometry of the acoustic system can be used to simulate and subtract this deterministic acoustic intensity component using, for example, the algorithm proposed in [3], [4] for radar signals.

In the current setup, each target (jellyfish) passage is obstructing the acoustic propagation channel between the emittermirror-receiver, which makes possible jellyfish monitoring. It acts as a conventional immersed $200 \mathrm{KHz}$ bandwidth ultrasound system in multi-static configuration: the emitted waveform is a linear Hamming windowed chirp. The received

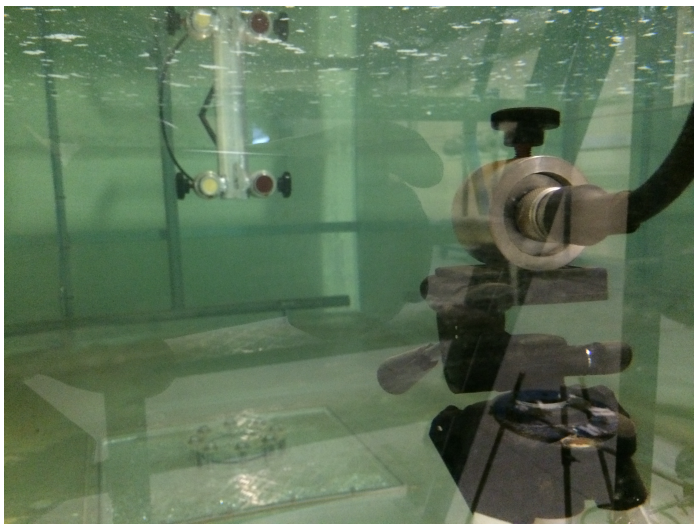

(a)
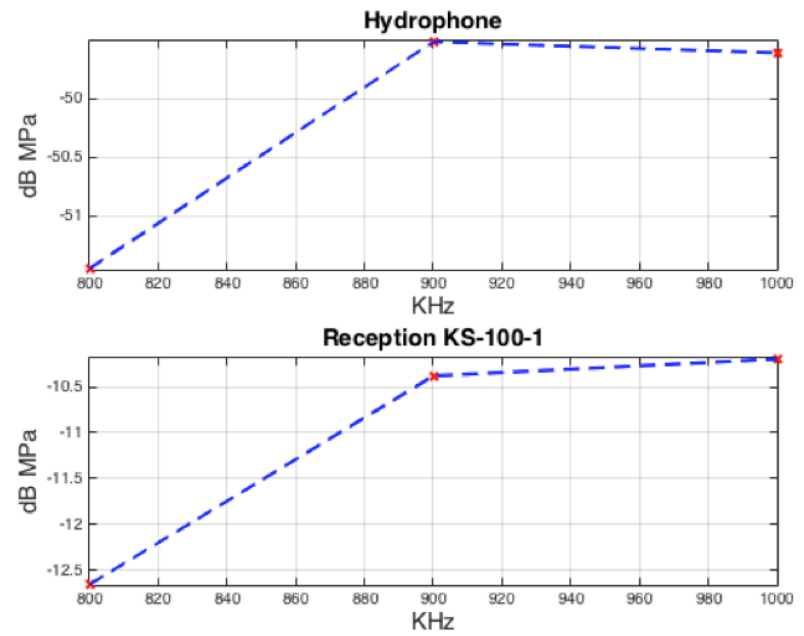

(b)

Fig. 3. (a) setup of the calibration procedure and (b) estimated transfer function for one KS-100-1 transducer.

signal is illustrated in Fig. 4.

For each ultrasound burst, the match filtering is performed at the reception in order to obtain its corresponding acoustic range profile as shown in Fig. 5. In order to avoid any eventual mismatches between the emitted and received acoustic wave (wave deformation induced by either the propagation channel or the conditioning system), the reference selection procedure proposed in [5], [6], [7] has been employed in the final processing algorithm.

\section{RESULTS AND DISCUSSION}

Two configurations have been tested in controlled water tank facilities:

- in a small test tank $(10 \mathrm{~m}$ radius $\times 50 \mathrm{~cm}$ depth, used for temporary transportation of annimals) with clear water and no turbulence,

- in a large tank $(10 \mathrm{~m} \times 20 \mathrm{~m} \times 5 \mathrm{~m}$, used in the standard aquarium show) with turbid water and in the presence of tides and air bubbles.

Figs. 6-(a) and 6-(b) illustrate the two small tank setup using the two species of jellyfish. Notice that underwater 

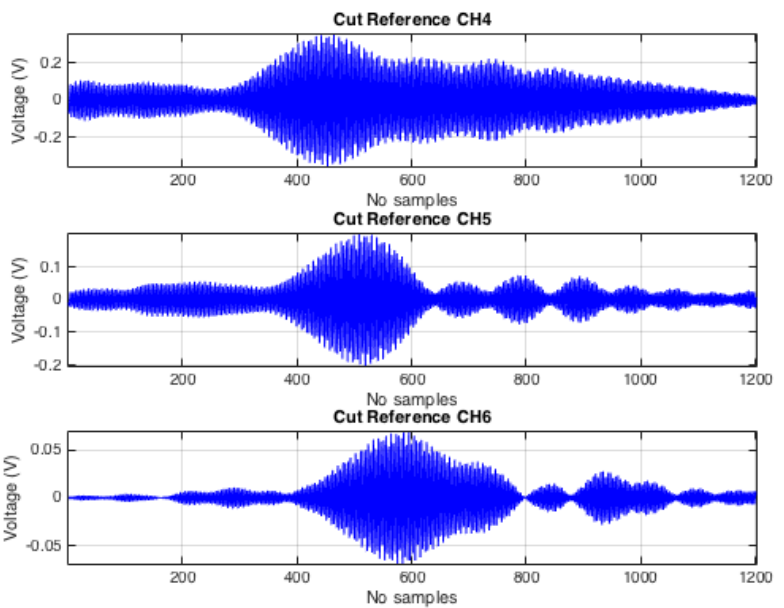

(a)
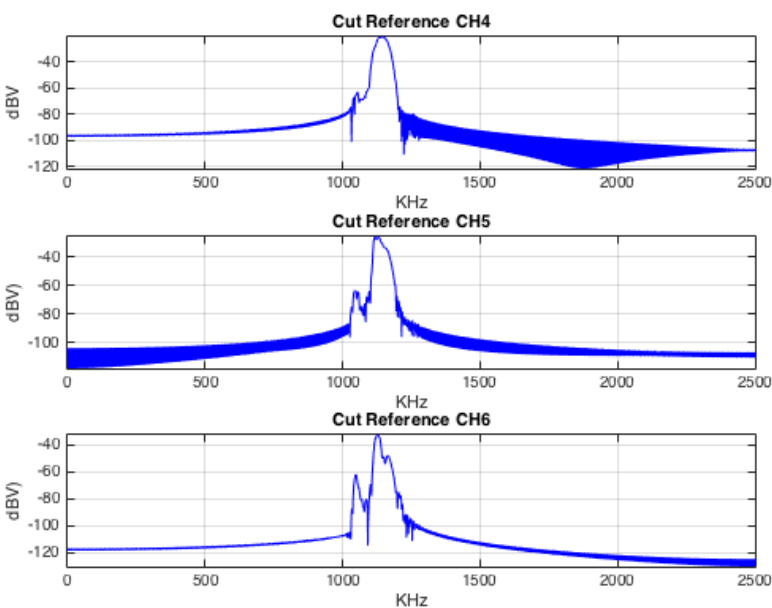

(b)

Fig. 4. (a) received acoustic signal (time domain) and (b) spectrum of the received signal.

cameras have been used for validation. The obtained results are shown in Figs. 6-(c) and 6-(d). The presented time series were obtained by taking only the maximum for each burst, after match filtering.

One can notice the time axis is relatively short with respect to a slow jellyfish passage. This is because the acquisition mode is not continuous and the time stamp of each burst was not taken into account for these preliminary results.

The jellyfish detection profiles can be observed on Fig. 7 for the large tank experimental setup, also. This time, the passage detection profile is more noisy, especially for species 1 .

\section{CONCLUSION}

The active ultrasound monitoring system presented in this paper offers an alternative option to monitor jellyfish passages in turbulent underwater environments. Based on the coupling of conventional active signal processing algorithms with novel acoustic channel equalization techniques, the main advantages
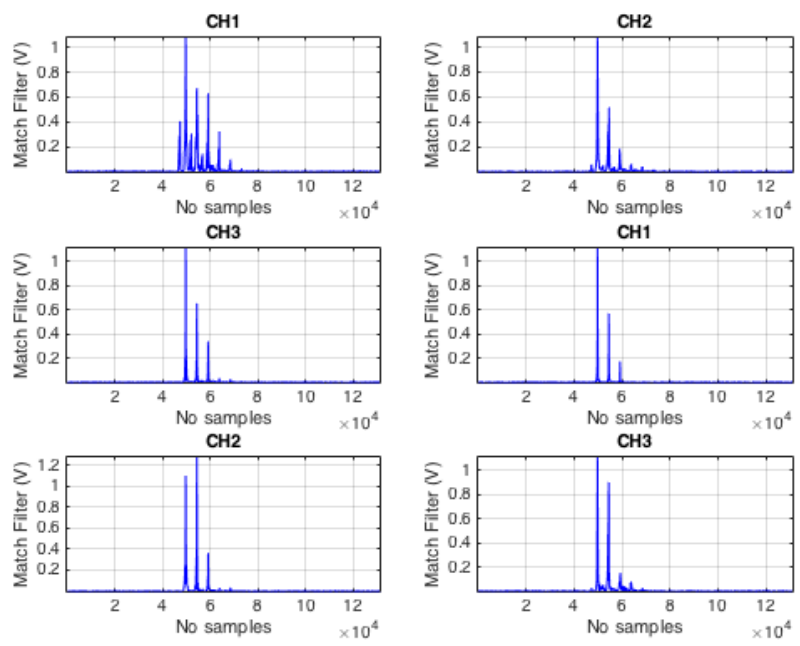

Fig. 5. Range profile after match filtering.

of the proposed system are its improved autonomy and the fact that it requires significantly less human intervention for monitoring and counting of jellyfish species. Future studies include the full performance analysis in real underwater conditions.

\section{ACKNOWLEDGMENT}

This work was supported by the FEDER project ACOUEAU. The authors would like to thank the Aquarium de Paris team, France, for both allowing access to our research team and for helping us with the jellyfish manipulation for the experimentation campaign.

\section{REFERENCES}

[1] L. Brotz, W.W.L. Cheung, K. Kleisner, E. Pakhomov, and D. Pauly, "Increasing jellyfish populations: trends in large marine ecosystems," Hydrobiologia, vol. 690, no. 1, pp. 3-20, 2012.

[2] P. Bernard, L. Berline, and G. Gorsky, "Long term (1981-2008) monitoring of the jellyfish Pelagia noctiluca (Cnidaria, Scyphozoa) on Mediterranean Coasts (Principality of Monaco and French Riviera)," Journal of Oceanography, Research and Data, vol. 4, pp. 1-10, 2011.

[3] A. Julea, G. Vasile, I. Petillot, E. Trouvé, M. Gay, J.M. Nicolas, and P. Bolon, "Simulation of SAR images and radar coding of georeferenced information for temperate glacier monitoring," in Proceedings of the International Conference on Optimization of Electrical and Electronic Equipment, Brasov, Romania, 2006, vol. 4, pp. 175-180.

[4] T. Landes, M. Gay, E. Trouvé, J.M. Nicolas, L. Bombrun, G. Vasile, and I. Hajnsek, "Simulation of SAR images and radar coding of georeferenced information for temperate glacier monitoring," in Proceedings of the International Conference on Optimization of Electrical and Electronic Equipment, Brasov, Romania, 2007, vol. 4, pp. 175-180.

[5] G. Vasile, F. Pascal, J.P. Ovarlez, P. Formont, and M. Gay, "Optimal parameter estimation in heterogeneous clutter for high-resolution polarimetric SAR data," IEEE Geoscience and Remote Sensing Letters, vol. 8, no. 6, pp. 1046-1050, 2011.

[6] A. Anghel, G. Vasile, C. Ioana, R. Cacoveanu, and S. Ciochina, "Modelbased parameter estimation of non-stationary signals using time warping and a measure of spectral concentration," in Proceedings of the IEEE International Conference on Acoustics, Speech, and Signal Processing, Brisbane, Australia, 2015, pp. 3706-3710.

[7] G. Vasile, G. d'Urso, E. de Oliveira, J. Guillet, and E. Lungu, "Reference selection for an active ultrasound wild salmon monitoring system," in Proceedings of the MTS/IEEE North American OCEANS conference, Washington, DC, USA, 2015, pp. 1-4. 


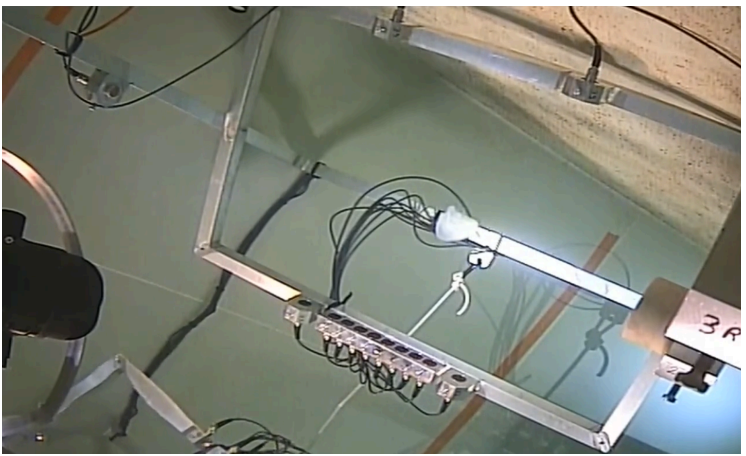

(a)

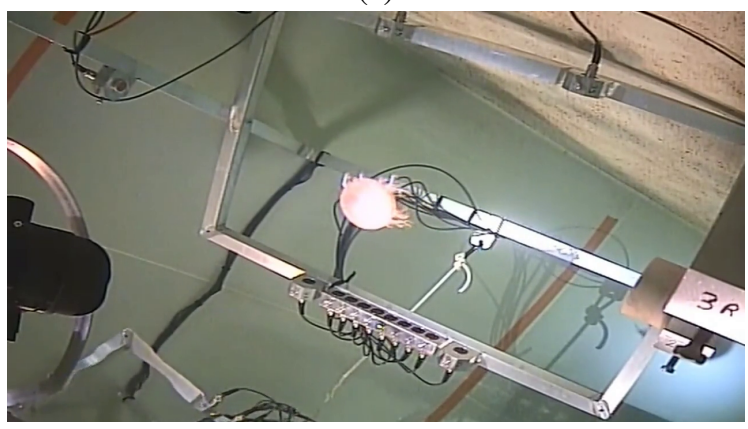

(b)
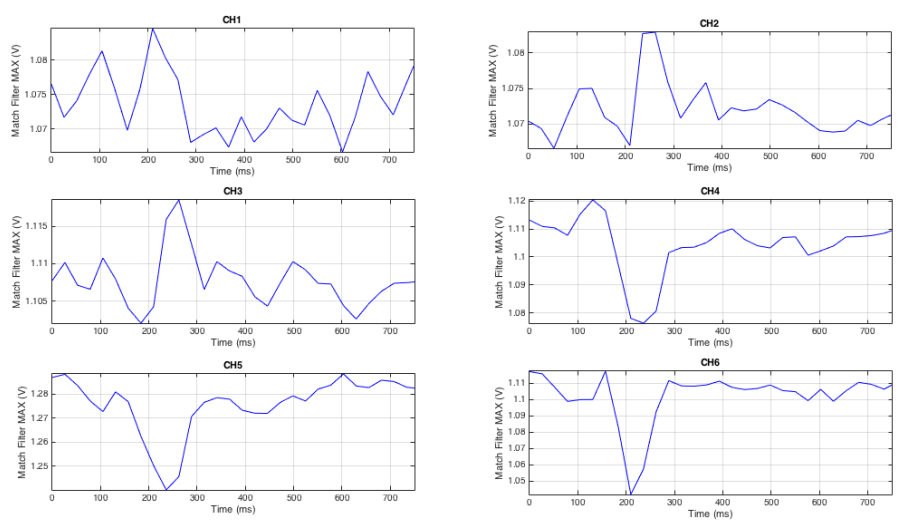

(c)
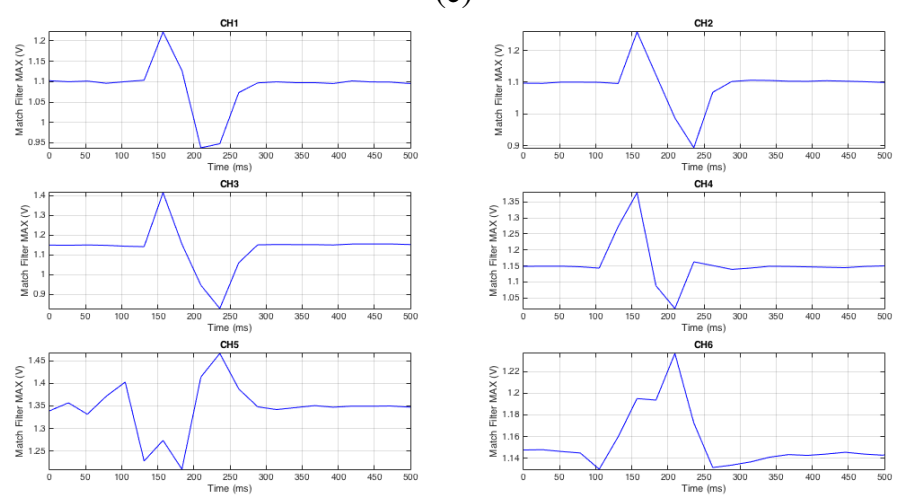

(d)

Fig. 6. Small test tank experimental setup (small circular test tank with 10 $\mathrm{m}$ radius $\times 50 \mathrm{~cm}$ depth with clear seawater): (a) species 1 , (b) species 2 . The maximum received acoustic signals time series after match filtering: (b) species 1 , (d) species 2 .

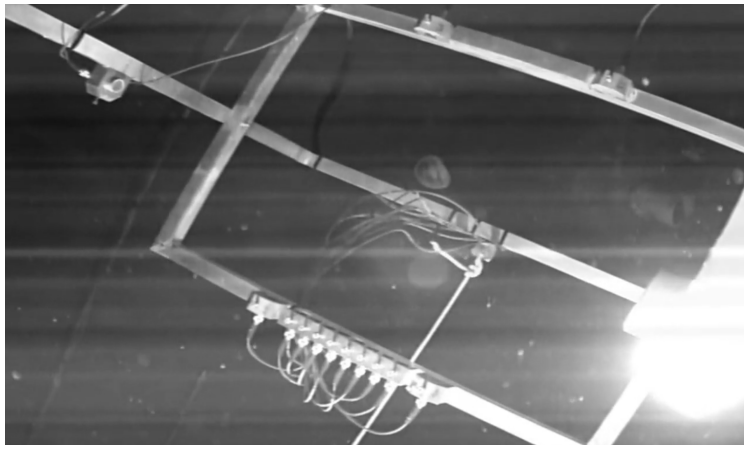

(a)

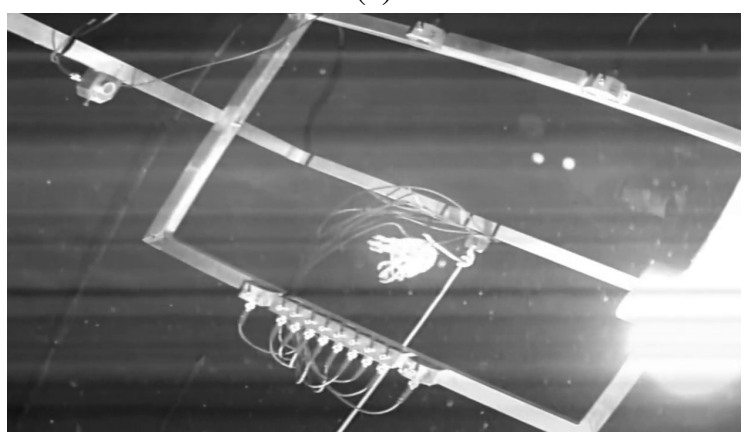

(b)
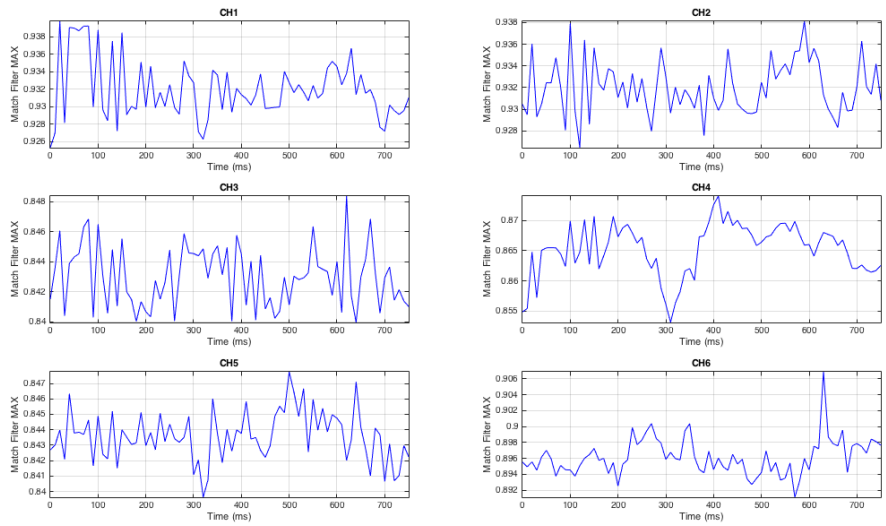

(c)
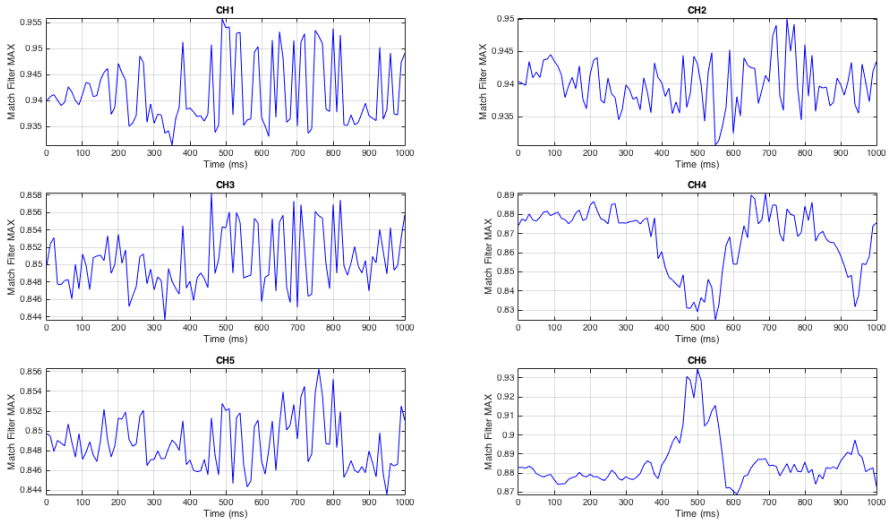

(d)

Fig. 7. Large test tank experimental setup (rectangular test tank with 10 $\mathrm{m} \times 20 \mathrm{~m} \times 5 \mathrm{~m}$, with turbulent seawater): (a) species 1 , (b) species 2 . The maximum received acoustic signals time series after match filtering: (b) species 1 , (d) species 2 . 